\title{
Transition metal catalysed Grignard-like allylic activation across tetragonal tin(II) oxide
}

\author{
PRADIPTA SINHA, MOLOY BANERJEE, ABHIJIT KUNDU and \\ SUJTT ROY* \\ Organometallics and Catalysis Laboratory, Chemistry Department, \\ Indian Institute of Technology, Kharagpur 721 302, India \\ e-mail: sroy@chem.iitkgp.ernet.in
}

\begin{abstract}
The reaction of allyl halide and a carbonyl compound under the aegis of tetragonal tin(II) oxide and catalytic $d^{8}, d^{10}$ metal complexes provides the corresponding homoallylic alcohol, via a novel allyl tin intermediate.
\end{abstract}

Keywords. Allylation; Grignard reagent; tin(II) oxide.

\section{Introduction}

Contemporary chemistry is characterized by the number and variety of topics, which cut across traditional divides. The interest in combining transition and main group elements to generate new structural motifs, often clusters, provides distinct opportunities in the field of catalysis. In this direction, ligand-assisted heterometallic cluster design is a welladapted approach ${ }^{1}$ and is best suited in cases where selectivity is the key concern in catalysis. A similar exercise, but in a ligand-free environment, is generally assumed to be non-selective, and moreover to pose significant diagnostic difficulties towards mechanistic elucidation. Our recent endeavour in this direction is the development of heterobimetallic $\mathrm{Sn}(\mathrm{II}) / \mathrm{Cu}(\mathrm{II})$ reagents for Grignard-like activation of organic halides, dichalcogenides and chalcogenides (scheme 1$)^{2}$.

We believe that one of the most important challenges in the 100-year old history of the Grignard-reaction ${ }^{3}$ is to find gateways towards the activation of organic halides in water and across a metal oxide matrix. We present in this paper novel findings pertaining to the Grignard activation of allyl halides across tetragonal tin(II) oxide ${ }^{4}$ under the influence of transition metal catalysts. Furthermore, in-situ and ex-situ mechanistic probing provides evidence towards the formation of novel organotin intermediates.

\section{Results and discussion}

The reaction chosen for the present study is the Barbier variation of the Grignard reaction, wherein the organic halide and a carbonyl compound react to provide the corresponding homoallylic alcohol ${ }^{5}$. With specific reference to carbonyl allylation via tin(II) salts, it was previously shown that allyltrihalostannane is formed as a reactive intermediates in the copper(I) catalysed reaction of stannous halide with allyl halide. A cursory inspection of the stereo-electronic features of tin(II) halides and that of tin(II)

\footnotetext{
*For correspondence
} 


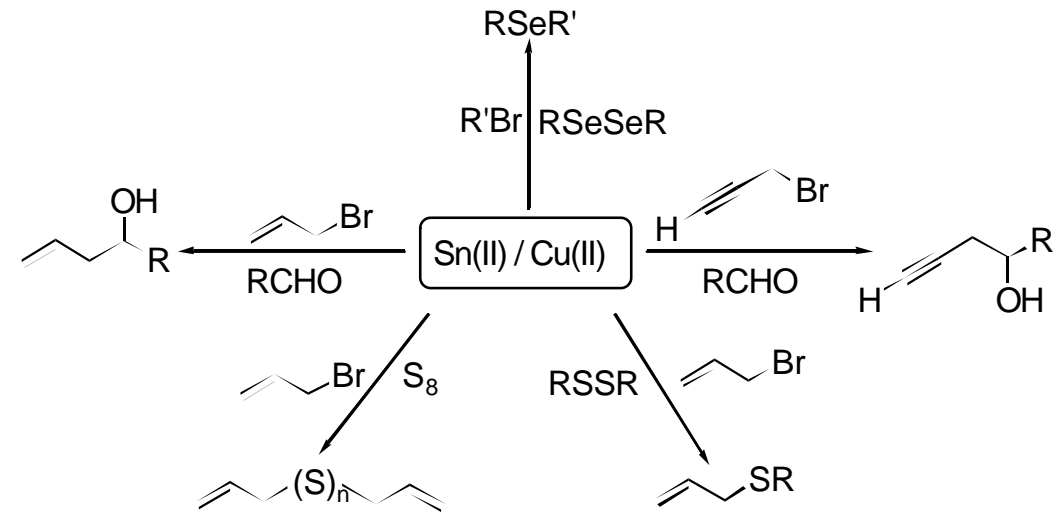

Scheme 1. Activation of organic halide, dichachalcogenides and chalcogenides using $\mathrm{Sn}(\mathrm{II}) / \mathrm{Cu}(\mathrm{II})$ reagent.

oxide provides immediate insight into the plausibility of a facile oxidative addition of organic halide across $\beta$-SnO. Disappointingly the very first test reaction conducted with allyl bromide and 4-chlorobenzaldehyde over $\beta$-SnO in dry THF failed to provide any product. A mere switch of the solvent system to THF- $\mathrm{H}_{2} \mathrm{O}(1: 1 v / v)$ afforded less than $10 \%$ of the desired alcohol (vide GC). Most remarkably, addition of catalytic amounts of (1 mol\% with respect to carbonyl) $\mathrm{Pt}(\mathrm{II}), \mathrm{Pd}(\mathrm{II}), \mathrm{Pd}(0), \mathrm{Rh}(\mathrm{I}), \mathrm{Cu}(\mathrm{I})$, or $\mathrm{Cu}(\mathrm{II})$ complexes/salts leads to facile reaction (table 1). The desired homoallylic alcohol is formed in good to excellent yield. The turnover frequencies of the catalysts are moderate to good (table 2). The present catalysts can also activate allyl chloride and allyl alcohol over $\beta$-SnO (table 2 , entries 4, 8, 6 and 9). It is noteworthy that non-functionalized allyl chlorides are otherwise poorly active in Grignard reactions, while allyl alcohols are almost inert. Finally in terms of selectivity the reactions are $100 \%$ rregioselective.

While mechanistic studies are underway in our laboratory, preliminary experiments clearly establish the formation of new tin-carbon bonded species during the course of the reaction. Thus, a mixture of $\beta-\mathrm{SnO}(2 \mathrm{mM})$, catalytic $\mathrm{Pd}_{2}(\mathrm{dba})_{3}(0.02 \mathrm{mM})$ and allyl bromide $(4 \mathrm{mM})$ in THF- $\mathrm{H}_{2} \mathrm{O}(99: 1 \mathrm{v} / \mathrm{v})$ was refluxed for $10 \mathrm{~h}$. Following filtration under argon, and solvent removal, the residue was examined by ${ }^{1} \mathrm{H}$ NMR. The spectrum (figure 1c) showed the formation of a new $\sigma$-allyl tin species characterized by allylic proton signals at $2.55 \mathrm{ppm}\left[{ }^{2} J\left({ }^{119} \mathrm{Sn}-{ }^{1} \mathrm{H}\right)=154 \mathrm{~Hz}\right]$, as compared to that of allyl bromide at $4.1 \mathrm{ppm}$ (figure 1a). No such species was detected in the reaction without catalyst (figure 1b). On the other hand, reaction of allyl bromide with $\operatorname{Pd}_{2}(\mathrm{dba})_{3}$ alone, showed signals (figure 1d) due to known $\pi$-allylpalladium intermediate ${ }^{6}$. So it is very clear that $\pi$-allylpalladium species assists the formation of the $\sigma$-allyl tin species (figure 2).

Further a mixture of $\beta \mathrm{SnO}(2 \mathrm{mM})$, catalytic $\mathrm{Pd}_{2}(\mathrm{dba})_{3}(0.02 \mathrm{mM})$ and allyl bromide $(4 \mathrm{mM})$ in $\mathrm{THF}-\mathrm{H}_{2} \mathrm{O}(99: 1 \mathrm{v} / \mathrm{v})$ was refluxed for $10 \mathrm{~h}$ and the reaction mixture upon direct injection into EIMS probe, resulted in major peaks at 351, 430, 478 (figure 3) corresponding to possible fragments $\left[(\text { allyl })_{2} \mathrm{Sn}_{2} \mathrm{O}_{2}-\mathrm{H}\right]^{+}, \quad\left[(\text { allyl })_{2} \mathrm{Sn}_{2} \mathrm{O}_{2} \mathrm{Br}-\mathrm{H}\right]^{+}$, and $\left[(\text { allyl })_{2} \mathrm{Sn}_{2} \mathrm{Br}_{2}\right]^{+}$. In each case MS peak simulation was carried out in assigning the fragments. The above fragments could well originate from the novel intermediate A 
(scheme 2). FAB and LSIMS studies are underway to further characterize the intermediate.

\section{Experimental methods}

\subsection{General methods}

All reactions were performed under an inert atmosphere of argon. Substituted allyl bromides were prepared from the corresponding alcohols (Lancaster) using standard protocol. Stannous chloride dihydrate (S D Fine Chemicals), Cupric chloride dihydrate (S D Fine Chemicals), allyl alcohol (SRL) and allyl chloride (SRL) were used as received. $\beta$ Tin(II) oxide, $\mathrm{PtCl}_{2}\left(\mathrm{PPh}_{3}\right)_{3}, \mathrm{Pd}_{2}(\mathrm{dba})_{3}, \mathrm{PdCl}_{2}\left(\mathrm{PPh}_{3}\right)_{2}$, copper(I) chloride, $\mathrm{RhCl}\left(\mathrm{PPh}_{3}\right)_{3}, \quad[\mathrm{Rh}(\mathrm{COD})(\boldsymbol{\mu} \mathrm{Cl})]_{2}$, catalysts were prepared rather easily as per the literature $^{7}$. All the starting materials were $>98 \%$ pure (vide NMR). Pre-coated silica gel $60 \mathrm{~F}_{254}$ (Merck) was used for thin layer chromatography and silica gel 60-120 mesh (SRL) was used for column chromatography.

${ }^{1} \mathrm{HNMR}$ spectra were recorded in $\mathrm{CDCl}_{3}$ and DMSO- $d_{6}$ on a Brucker-300 spectrometer. Chemical shifts are reported in $\delta(\mathrm{ppm})$ relative to TMS as internal

Table 1. List of catalysts

\begin{tabular}{ll}
\hline $\mathrm{Pd}_{2}(\mathrm{dba})_{3}$ & a \\
$\mathrm{Pd}\left(\mathrm{PPh}_{3}\right)_{2} \mathrm{Cl}_{2}$ & b \\
$\mathrm{Pt}\left(\mathrm{PPh}_{3}\right)_{2} \mathrm{Cl}_{2}$ & c \\
$\mathrm{Rh}\left(\mathrm{PPh}_{3}\right)_{3} \mathrm{Cl}$ & d \\
{$[\mathrm{Rh}(\mathrm{COD})(\mu-\mathrm{Cl})]_{2}$} & e \\
$\mathrm{CuCl}$ & $\mathbf{f}$ \\
$\mathrm{CuCl}_{2} \cdot 2 \mathrm{H}_{2} \mathrm{O}$ & g \\
\hline
\end{tabular}

Table 2. Activation of allyl halide and allyl alcohol.

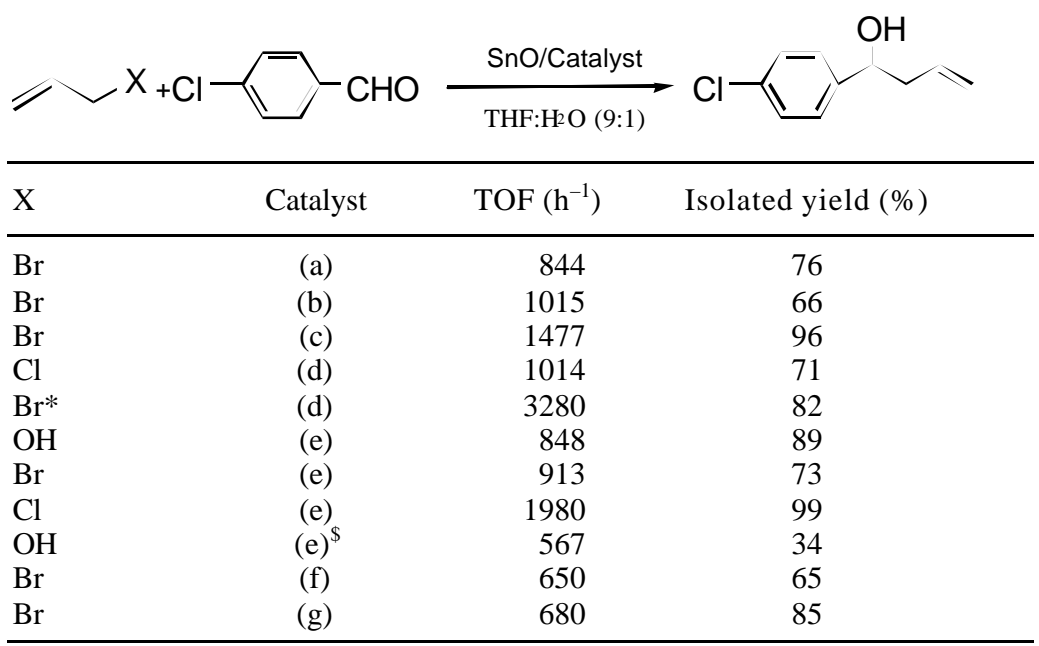

${ }^{\$}$ Dioxane- $\mathrm{H}_{2} \mathrm{O}(9: 1 \mathrm{v} / \mathrm{v})$ has been used as solvent

*1-Bromo-but-2-en has been used to test $\gamma$-regioselectivity 
(d)

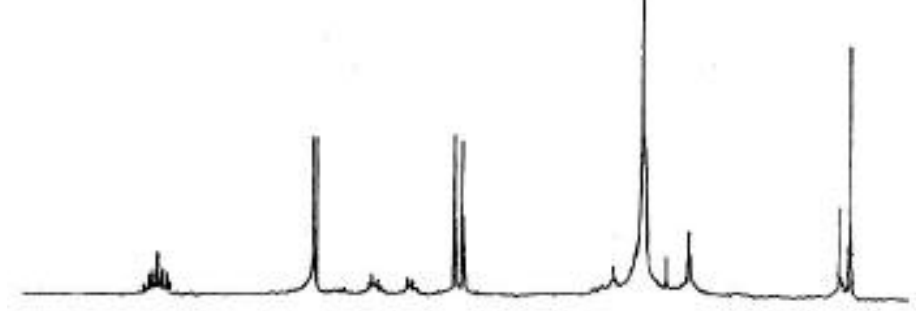

(c)
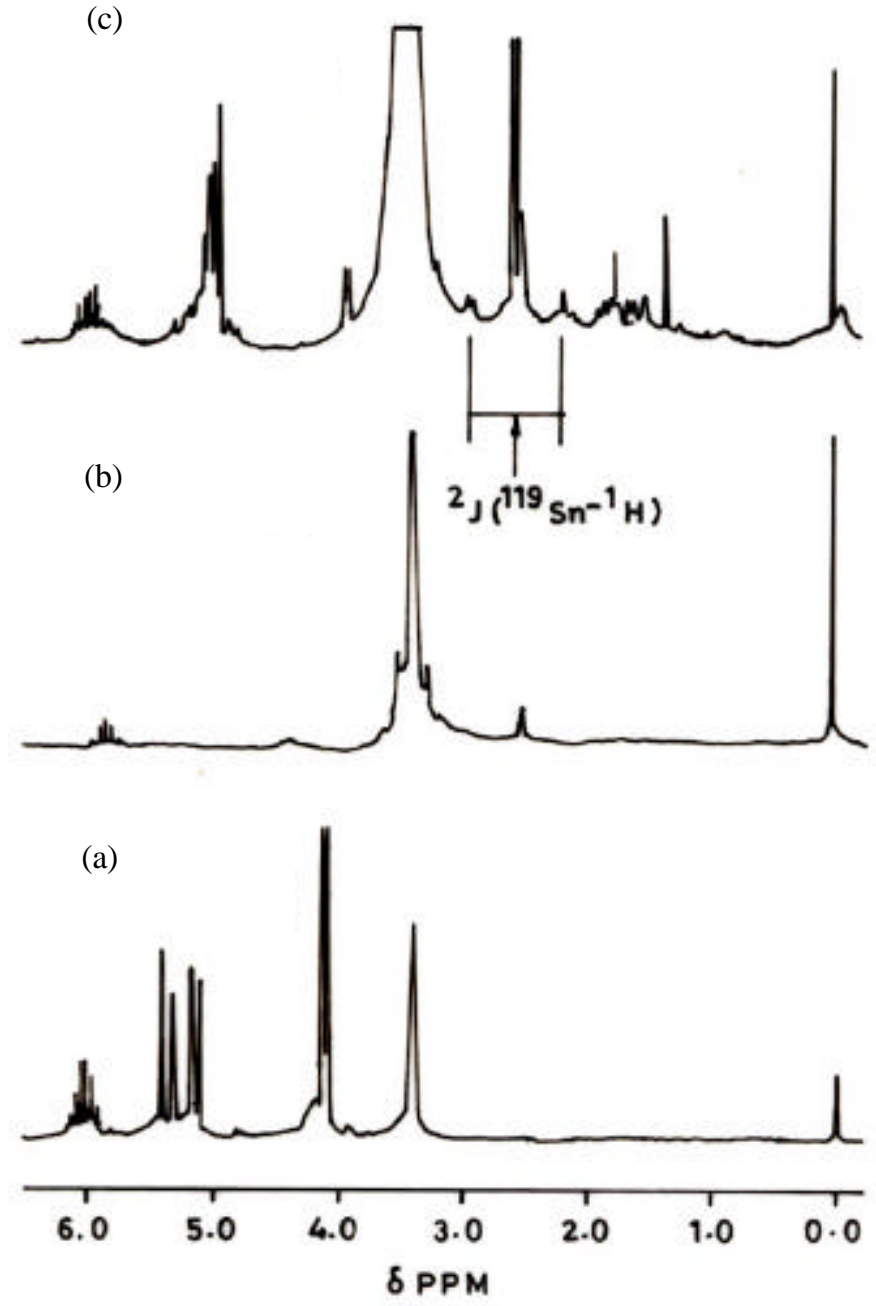

Figure 1. ${ }^{1} \mathrm{H}$ NMR spectra in DMSO- $d_{6}$ of (a) allyl bromide; (b) residue from the reaction of $\beta-\mathrm{SnO} /$ allyl bromide; (c) residue from the reaction of $\beta-\mathrm{SnO} /$ allyl bromide/ catalytic $\mathrm{Pd}_{2}(\mathrm{dba})_{3}[\mathrm{dba}=$ dibenzylideneacetone $]$; (d) ${ }^{1} \mathrm{H}$ NMR spectra in $\mathrm{CDCl}_{3}$ of $\pi$-allyl palladium species. 


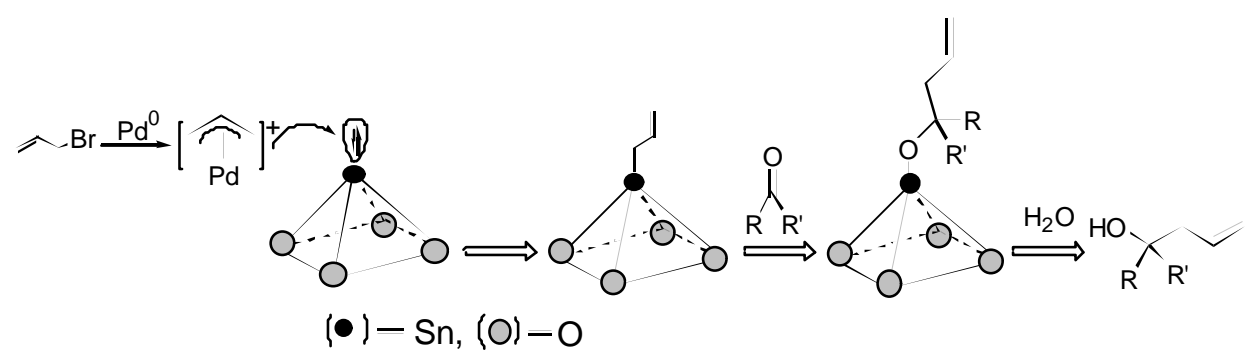

Figure 2. $\pi$-Allylpalladium attacks tetragonal tin(II) oxide.

standard. EIMS (70 eV) spectra were recorded using VG Autospec M mass spectrometer. GC analysis was carried out on a Chemito-8610 instrument using Supelcowax-10 30, capillary column.

3.2 Typical procedure for the syntheses of homoallylic alcohols using $\beta-S n O$ and $[\mathrm{Rh}(\mathrm{COD})(\boldsymbol{\mu} \mathrm{Cl})]_{2}$ as catalysts

A mixture of 4-chlorobenzaldehyde (140 mg, $1 \mathrm{mM})$ and allyl chloride (153 mg, $2 \mathrm{mM}$ ) in tetrahydrofuran $(2 \mathrm{ml})$ was added slowly to a refluxing solution containing $\beta-\mathrm{SnO}$ $(202 \mathrm{mg}, \quad 1.5 \mathrm{mM})$ and $[\mathrm{Rh}(\mathrm{COD})(\boldsymbol{\mu t C l})]_{2} \quad(5 \mathrm{mg}, 0.01 \mathrm{mM})$ in tetrahydrofuran-water ( $2.5 \mathrm{ml}-0.5 \mathrm{ml})$ under argon. The mixture was further refluxed for $5 \mathrm{~h}$ (TLC monitoring on silica gel, eluent: $n$-hexane: ethyl acetate 9:1.) An aqueous solution of ammonium fluoride $(15 \%, 10 \mathrm{ml})$ was added to the reaction mixture and organic layer was extracted with diethyl ether $(3 \times 10 \mathrm{ml})$, washed with water $(2 \times 10 \mathrm{ml})$, brine $(2 \times 10 \mathrm{ml})$ and dried over magnesium sulphate. Solvent removal followed by column chromatography (eluent $n$-hexane: ethyl acetate 9:1) afforded pure 1-(4-chlorophenyl)-3-buten-1-ol yield: (181 mg, 99\% w.r.t. aldehyde).

${ }^{1} \mathrm{H}$ NMR $\left(\mathrm{CDCl}_{3}\right): \delta 2.46(t, 2 \mathrm{H}, J=6.4 \mathrm{~Hz}), 4.68(t, 1 \mathrm{H}, J=6.4 \mathrm{~Hz}), 5.06-5.21(\mathrm{~m}$, $2 \mathrm{H}), 5.64-5.88(m, 1 \mathrm{H}), 7.28(s, 5 \mathrm{H})$; EIMS $m / z$ (rel. abundance): $182\left(M^{+},<1\right), 164(<2)$, 141 (100), 143 (32), 129 (5), 113 (8), 77 (10).

\subsection{Typical procedure for the syntheses of homoallylic alcohols using $\beta$-SnO and} $\mathrm{PtCl}_{2}\left(\mathrm{PPh}_{3}\right)_{2}$ as catalysts

Similar procedure as above was followed except that the catalyst is $\mathrm{PtCl}_{2}\left(\mathrm{PPh}_{3}\right)_{2}(8 \mathrm{mg}$, $0.01 \mathrm{mM})$ and the halide used is 1-bromobut-2-en $(270 \mathrm{mg}, 2 \mathrm{mM})$, which afforded pure 1-(4-chlorophenyl)-2-methylbut-3-en-1-ol after $2.5 \mathrm{~h} \quad$ yield: $\quad(161 \mathrm{mg}, \quad 82 \%$ w.r.t. aldehyde).

${ }^{1} \mathrm{H}$ NMR $\left(\mathrm{CDCl}_{3}\right)$ : (Mixture of two diastereoisomers: anti:syn 55:45) $\delta$ (anti isomer) $0.88(d, 3 \mathrm{H}, J=5 \mathrm{~Hz}), 2.19(b r s, 1 \mathrm{H},-\mathrm{OH}), 2.35-2.60 \quad(m, 1 \mathrm{H}), 4.33(d, 1 \mathrm{H}$, $J=7.57 \mathrm{~Hz}), 5 \cdot 0-5.24(m, 2 \mathrm{H}), 5.65-5.77(m, 1 \mathrm{H}), 7.22-7.34(m, 4 \mathrm{H}) ; \delta$ (syn isomer) $0.99(d, 3 \mathrm{H}, J=5 \mathrm{~Hz}), 1.92(b r \quad s, 1 \mathrm{H},-\mathrm{OH}), 2.35-2.60(m, 1 \mathrm{H}), 4.59(d, 1 \mathrm{H}$, $J=7.57 \mathrm{~Hz}), \quad 5 \cdot 0-5 \cdot 24 \quad(m, 2 \mathrm{H}), \quad 5 \cdot 65-5.77 \quad(m, 1 \mathrm{H}), 7 \cdot 22-7.34 \quad(m, 4 \mathrm{H}) ;$ EIMS $\mathrm{m} / \mathrm{z}$ (rel. abundance): $196\left(M^{+},<1\right), 178(<1), 163(<1), 143$ (31), 141 (100), 113 (14), 77 (41), 55 (8). 


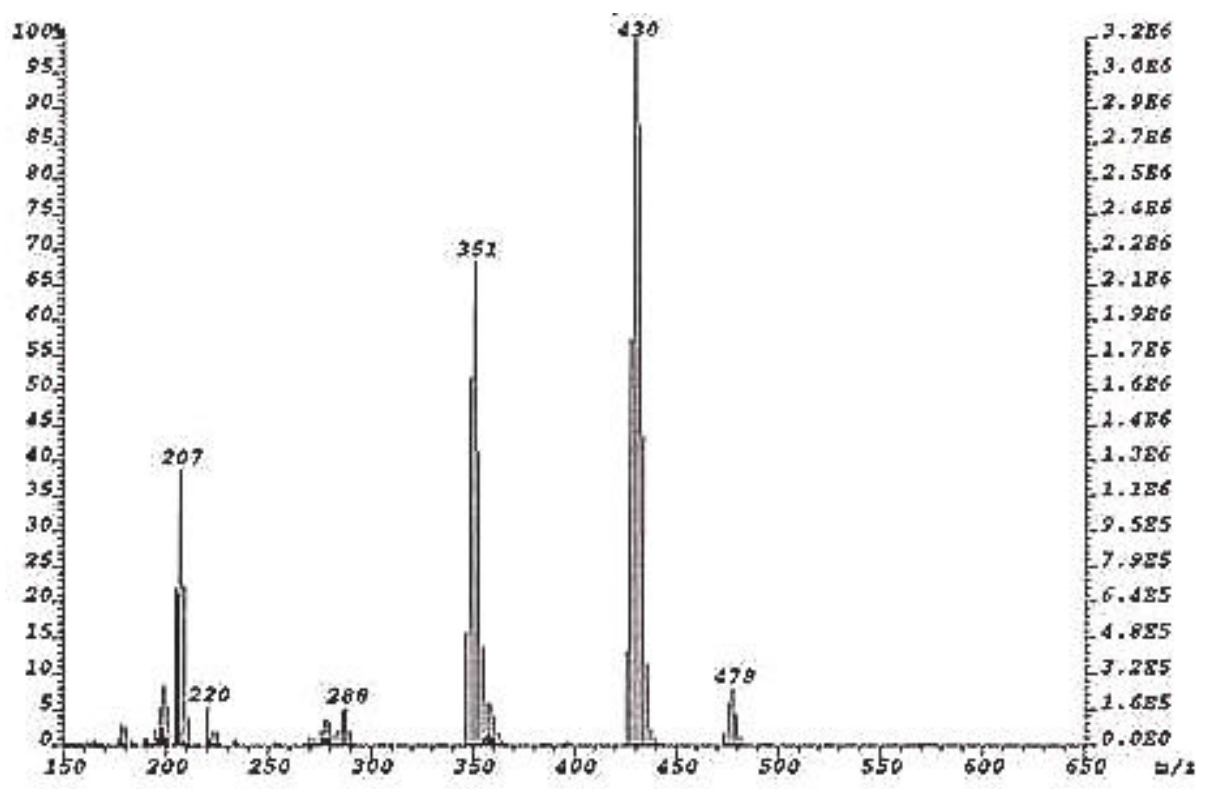

Figure 3. In situ EIMS spectrum from the reaction of $\beta$-SnO, catalytic $\mathrm{Pd}_{2}\left(\mathrm{dba}_{3}\right.$ and allyl bromide in THF- $\mathrm{H}_{2} \mathrm{O}$ showing major peaks at 351, 430, 478.

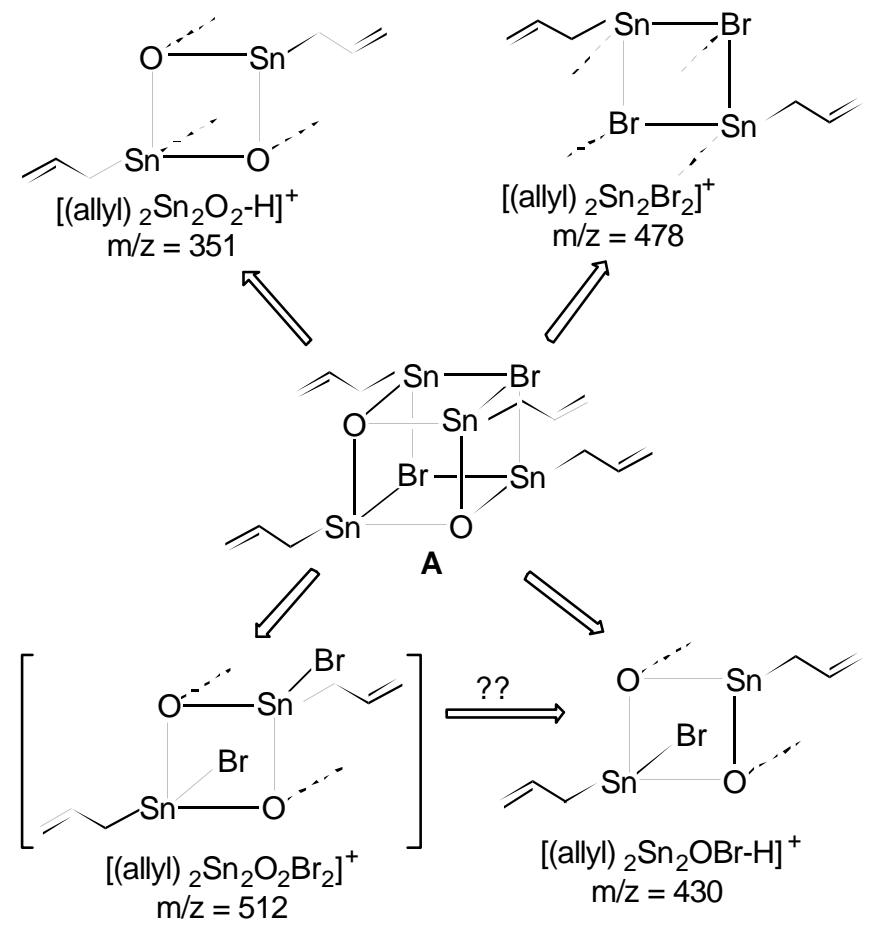

Scheme 2. Probable structure of the intermediate $\mathbf{A}$ from which fragments peaks were generated in EIMS spectra. 


\section{Acknowledgements}

This work is supported by the Council of Scientific and Industrial Research, New Delhi and Department of Scientific and Technology, New Delhi. Fellowships from the University Grants Commission, New Delhi (to PS) and the CSIR (to AK and MB) is gratefully acknowledged.

\section{References}

1. Fenske D 1994 In Clusters and colloids-from theory to applications (ed.) G Schmid (Weinheim: VCH)

2. (a) Sinha P and Roy S 2001 J. Chem. Soc., Chem. Commun. 1798; (b) Sinha P, Kundu A, Roy S Prabhakar S, Vairamani M, Sankar A R and Kunwar A C 2001 Organometallics 20 157; (c) Kundu A and Roy S 2000 Organometallics 19 105; (d) Kundu A, Prabhakar S, Vairamani M and Roy S 1999 Organometallics 18 2782; (e) Kundu A, Prabhakar S, Vairamani M and Roy S 1997 Organometallics 164796

3. (a) Barbier P 1898 Comp. Rend. 128 110; (b) Grignard V 1900 Comp. Rend. 1301322

4. (a) Donaldson J D 1967 Prog. Inorg. Chem. 8 287; (b) Harrison P J 1989 Chemistry of tin (New York: Blackie) pp 221; (c) Greenwood N N and Earnshaw A 1989 Chemistry of the elements (Oxford: Pergamon Press)

5. (a) Rousch W R 1991 In Comprehensive organic synthesis (eds) B M Trost, I Fleming and C H Heathcock (Oxford: Pergamon Press) vol. 2, pp 1, and related chapters; (b) Marshall J A 1996 Chem. Rev. 96 31; (c) Thomas E J 1994 Chemtracts-Org. Chem. 7 207; (d) Wakefield B J 1995 Organomagnesium methods in organic chemistry (New York: Academic Press) (e) Ito A, Kishida M, Kurusu Y and Masuyama Y 2000 J. Org. Chem. 65494

6. Maitilis P (ed.) 1971 The organic chemistry of palladium (New York: Academic Press) vol. 1, 2

7. (a) Brauer G (ed.) 1963 Handbook of preparative inorganic chemistry (New York: Academic Press) vol. 1; (b) Brauer G (ed.) 1965 Handbook of preparative inorganic chemistry (New York: Academic Press) vol. 2; (c) Bailar J C (Jr) and Itatori H 1965 Inorg. Chem. 4 1618; (d) Herrmann W A and Salzer A (eds) 1996 Synthetic methods of organometallic and inorganic chemistry (New York: George Thieme Verlag) vol. 1 and 7 